\title{
Withdrawal History, Private Information, and Bank Runs
}

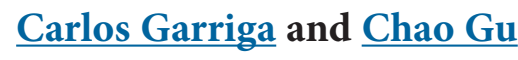

\begin{abstract}
This paper provides a simple two-depositor, two-stage model to understand how a bank's withdrawal history affects an individual's decision about withdrawals, which could possibly trigger bank runs. Individual depositors have private information about their personal consumption types and receive noisy private signals about the quality of the bank's portfolio. Depositors make publicly observable withdrawal decisions in sequence. Computed examples indicate that the optimal contract contingent on withdrawal histories can tolerate bank runs. These runs are triggered by unfavorable signals about a bank's portfolio, and early liquidation of unsuccessful investments can avoid future losses. Because the signals are private, a depositor's action is the only way to partially reveal his private information. A runadmitting bank contract allows information to be revealed. However, if signals are too noisy, bank runs may occur too often when fundamentals are strong. In this case, a bank would offer a run-proof contract. Given the relevant role of information, a policy that makes private information public would be useful to improve welfare and eliminate bank runs. (JEL C73, D82, E59, G21)
\end{abstract}

Federal Reserve Bank of St. Louis Review, July/August 2012, 94(4), pp. 305-20.

$\mathbf{T}$ he recent financial crises have drawn considerable attention on the regulation of financial intermediaries. One question that arises is whether bank runs should be prevented in any circumstance. To answer this question, we first need to understand the underlying conditions that prompt bank runs. One strand of the literature, following Diamond and Dybvig (1983), argues that banks and bank runs are inherently intertwined because banks' contracts provide short-term liquidity, whereas banks' portfolios mature only in the long term. As a result, a panic-based bank run is self-fulfilling even in the absence of uncertainty about fundamentals and is not efficient. Some institutional arrangements-for example, deposit insurance or the promise from the central bank to serve as the lender of last resort-can prevent panic-based bank runs by providing sufficient liquidity should a run occur.

Another strand in the literature attributes the runs to fundamentals. 1 The view on fundamental-based bank runs argues that bank runs occur when depositors receive negative information about their bank's portfolio returns or about an aggregate liquidity shock. Unlike

Carlos Garriga is a research officer and economist at the Federal Reserve Bank of St. Louis. Chao Gu is an assistant professor of economics at the University of Missouri-Columbia; she thanks Karl Shell for guidance.

(c) 2012, The Federal Reserve Bank of St. Louis. The views expressed in this article are those of the author(s) and do not necessarily reflect the views of the Federal Reserve System, the Board of Governors, or the regional Federal Reserve Banks. Articles may be reprinted, reproduced, published, distributed, displayed, and transmitted in their entirety if copyright notice, author name(s), and full citation are included. Abstracts, synopses, and other derivative works may be made only with prior written permission of the Federal Reserve Bank of St. Louis. 


\section{Garriga and Gu}

panic-based runs, fundamental-based runs are not necessarily inefficient because liquidating unsuccessful investments early can mitigate future losses.

In both strands of the literature, the arrival of information is the factor that determines whether a bank run occurs. For panic-based bank runs, the realization of an exogenous variable,

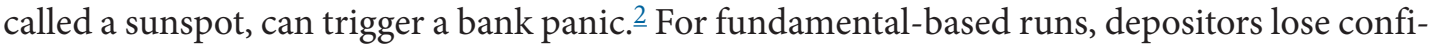
dence when there is unfavorable news about their bank's performance. In either approach it is generally assumed that upon receiving information depositors need to make a simultaneous withdrawal decision without observing the actions of others.

In reality, at least some withdrawals are based on the information about previous withdrawals by others. $\underline{3}$ This sequential process of learning from the observed withdrawal history is important to understand not only bank runs, but also whether banks can use the process of revelation of information to design their deposit contracts.

The objective of this paper is to understand how a bank's withdrawal history affects an individual's decision about withdrawals, which could possibly trigger bank runs. A dynamic model is necessary to formalize the revelation of the withdrawal history. The model is a simple twostage game with two depositors and private information. In the game, bank runs are driven by signals on the fundamentals as opposed to sunspots.

In the model, the depositors receive a private signal about their liquidity needs and a private noisy signal about the quality of the bank's portfolio. Depositors make withdrawal decisions in sequence at a given stage and the withdrawal decisions are publicly observable. The first depositor's action to withdraw or to wait can partially reveal his private signal about the bank's portfolio, which affects the belief of the second depositor and thus his withdrawal decision. Under some parameterization, the optimal contract admits an equilibrium in which depositors' strategies are contingent on their private signals and observed withdrawals.

A dynamic model explains some empirical results on bank runs that cannot be explained by a static model. For example, during the 2001 run on Turkish special finance houses, $\underline{4}$ depositors made sequential withdrawals influenced by the history of withdrawals by others, as noted by Starr and Yilmaz (2007, p. 1114): "Increased withdrawals by moderate-size account holders tended to boost withdrawals by [their] small counterparts, suggesting that the latter viewed the former as informative with respect to the SFH's [special finance house's] financial condition." $\underline{5}, \underline{6}$

Our model, although simple, sheds some light on whether bank runs should be completely prevented in an environment of private information. Computed examples show that in some economies a contract that permits bank runs is optimal, whereas in other economies a run-proof contract is optimal. This result is in line with the literature proposing that, if the probability of bank runs is low, a bank contract tolerates bank runs as depositors receive more consumption insurance during normal times. Furthermore, in the environment considered here, a bank run is driven by the information about a bank's portfolio return. In other words, it is driven by fundamentals. When fundamentals are weak, it is optimal for the bank to liquidate its portfolio to avoid future losses.

Since information is private, the only way that depositors can reveal their information is by their actions. A run-admitting contract allows depositors to do so, whereas a run-proof contract does not. However, (i) because a depositor's decision to withdraw carries noisy information about the signals he receives (the depositor might need to consume immediately or might receive an 
unfavorable signal about the quality of the bank's portfolio) ${ }^{\underline{7}}$ and (ii) because the information itself is imperfect, bank runs can occur when fundamentals are strong. In these cases, runs are misled. If the probability of such misled runs is high, a run-proof contract is better.

The payments to the depositors in our model have two functions. First, they price fundamental risks. Second, depending on the quality of information, they give depositors an incentive to reveal or to hide their private information. Our results imply that pricing risk and incentive appropriately is the key to making financial markets efficient, $\underline{8}$ although ex post inefficient runs can occur as a result of imperfect information.

To show the importance of information, it is useful to solve a numerical example where signals on portfolio returns are public and compare it with the one with private signals. With public signals welfare is higher and, most importantly, there are no bank runs. ${ }^{9}$ Hence, policymakers may make more effort to publicize the information of the fundamentals to improve welfare.

We focus on the numerical examples that yield a unique equilibrium. Hence, there is no sunspot-driven run (or panic-based run) in this paper. Although some bank runs occur when fundamentals are strong, since the runs are triggered by (imperfect) signals on fundamentals, these are still fundamental-based runs in our view.

Runs on commercial banks have been rare in the United States since the introduction of deposit insurance. However, runs on the shadow banking system were the important events in the recent financial crisis (see Gorton, 2010, and Anderson and Gascon, 2009). Our model, which uses the customary terminology in the literature with regard to bank runs, applies to general financial intermediaries subject to systemic financial crises.

The rest of the paper is organized as follows: The next section introduces the model setup and is followed by a discussion of the equilibrium given a banking contract. Next we calculate some examples of optimal contracts and then offer an example of an optimal contract in an economy with public signals. The final section summarizes our findings and conclusion.

\section{THE MODEL}

Time. There are three periods, indexed by $t=0,1,2$. Period 0 is a planning period called ex ante. Periods 1 and 2 are ex post periods. Period 1 is divided into two stages.

Depositors' endowment and preferences. There are two depositors. Each depositor is endowed with one unit of consumption good ex ante and nothing ex post. Each depositor has probability $\alpha$ to become impatient in period 1 and probability $1-\alpha$ to be patient. An impatient depositor values consumption only at $t=1$. His utility is described by $u\left(c_{1}\right)$, where $c_{1}$ is the consumption at $t=1$. A patient depositor's utility is described by $u\left(c_{1}+c_{2}\right)$, where $c_{2}$ denotes the consumption at $t=2$. The utility function is strictly increasing, strictly concave, and twice differentiable. The coefficient of relative risk aversion, $x u^{\prime}(x) / u^{\prime \prime}(x)$, is greater than 1 when $x \geq 1$. Whether a depositor is patient or impatient is revealed to the individual depositor at some stage in period 1 .

Technologies. The consumption good can be stored at no cost. It can also be invested in a risky technology. The investment must be made ex ante and takes two periods to mature. The return on the investment can be either $\bar{R}>1$ or $\underline{R}<1$ at $t=2$. The ex ante probability of receiving $\bar{R}$ is $p_{0}$. If the investment is liquidated at $t=1$, the return is 1 . Because the investment yields the 


\section{Garriga and Gu}

same return as storage at $t=1$, all consumption goods will be placed in the risky technology at $t=0$ and will be partially or fully liquidated at $t=1$, depending on the events occurring at $t=1$.

Withdrawal stages and information. Period 1 is divided into two stages. At each stage, one depositor is informed of a pair of signals. One signal tells him precisely his consumption type; the other imperfectly tells him the investment returns. The signal on investment return is accurate with probability $q$, where $q \geq 0.5$. That is,

$$
\operatorname{Pr}\left(S_{i}=H \mid R=\bar{R}\right)=\operatorname{Pr}\left(S_{i}=L \mid R=\underline{R}\right)=q,
$$

where $S_{i}$ denotes depositor $i$ 's private signal of investment return. Depositors have an equal chance to receive signals at stage 1 . The depositor who receives the signals at the first stage is called depositor 1 ; the other is depositor 2 .

Each depositor can make withdrawals when he receives signals in period 1. If he does not withdraw in period 1 , he receives payment in period 2 . For convenience, a depositor can withdraw in period 1 only at the stage when he receives information. Depositors' actions are publicly observable. .10 Because there are only two depositors and two stages, allowing depositors to withdraw at any stage adds only two possible simultaneous-move games to each stage and does not change the main results.

The contract. A competitive bank offers a contract to depositors ex ante. For convenience, the minimum deposit amount that the bank accepts is one unit of a consumption good. The bank allocates the funds between storage and investment and makes payments to depositors upon withdrawals. The banking contract considered here pays depositors contingent on the withdrawal history. $11, \underline{12}$ The contract specifies the payments to withdrawals at $t=1$ depending on the number of withdrawals that have been made and the payments to withdrawals at $t=2$ depending on the number of withdrawals at $t=1$ and the return on investment. Let $x_{i} \in\{0,1]$ denote depositor $i$ 's action in period 1 , where 0 indicates wait and 1 indicates withdraw. Let $c^{1}\left(x_{1}\right)$ be the payment to depositor 1 at stage 1 , where $c^{1}(0)=0$, and let $c^{1}\left(x_{1}, x_{2}\right)$ denote payment to depositor 2 at stage 2 , where $c^{1}\left(x_{1}, 0\right)=0$. Similarly, let $c^{2}\left(x_{1}, x_{2}, R\right)$ denote payments at $t=2$. All instances of $c^{1}$ and $c^{2}$ satisfy the following resource constraints:

$$
\begin{gathered}
c^{1}\left(x_{1}\right)+c^{1}\left(x_{1}, x_{2}\right) \leq 2, \\
\left(2-x_{1}-x_{2}\right) c^{2}\left(x_{1}, x_{2}, R\right) \leq\left[2-c^{1}\left(x_{1}\right)-c^{1}\left(x_{1}, x_{2}\right)\right] \max \{1, R\}, \\
\left(2-x_{1}-x_{2}\right) c^{2}\left(x_{1}, x_{2}, R\right) \geq\left[2-c^{1}\left(x_{1}\right)-c^{1}\left(x_{1}, x_{2}\right)\right] \min \{1, R\} .
\end{gathered}
$$

Timing of the banking game. The timeline of the banking game can be summarized as follows:

$t=0$ :

- The bank announces the contract.

- Depositors make deposit decisions. 
$t=1$ :

Stage 1:

- Depositor 1 receives signals about his consumption type and productivity.

- He decides whether to withdraw.

Stage 2:

- Depositor 2 receives signals about his consumption type and productivity.

- He decides whether to withdraw.

$t=2$ :

- The bank allocates the remaining resources to depositors who have not withdrawn in period 1 .

The postdeposit game starts after depositors make deposits at the bank. An individual depositor decides when to withdraw. A bank run occurs if at least one patient depositor withdraws. Knowing what depositors will do in the postdeposit game, a representative bank offers a contract that maximizes the ex ante expected utility of the depositors. Depositors determine whether to deposit at the bank or stay in autarky. Starting at $t=0$, the entire game is called the predeposit game. Solving the model backward, as in Peck and Shell (2003), requires starting with the postdeposit game and describing the equilibrium given a contract. Then the predeposit game is completed by comparing the expected utilities in autarky with those in a banking economy.

\section{THE POSTDEPOSIT GAME}

The equilibrium concept is a perfect Bayesian equilibrium in which the strategies of the depositors are optimal given the depositors' beliefs about investment returns and the beliefs are updated by Bayes' rule whenever possible.

Let $x_{n}^{i}$ and $p_{n}^{i}$ denote the strategy and posterior belief that the return is high, respectively, of depositor $i$ at stage $n$. Given each depositor's preferences and the structure of the game, depositor 1 's strategy at stage 1 is

$$
x_{1}^{1}=1 \text { if impatient and } x_{1}^{1}=1 \text { with probability } \theta_{S_{1}}^{1} \text { if patient, }
$$

and depositor 2's strategy at stage 2 is

$$
x_{2}^{2}=1 \text { if impatient and } x_{2}^{2}=1 \text { with probability } \theta_{x_{1}, S_{2}}^{2} \text { if patient. }
$$

Since depositors can make withdrawals only at their informed stage, $x_{n}^{i}=0$ when $n \neq i$.

\section{Bayesian Updates}

Suppose a depositor has prior belief $p$ at the beginning of a stage. Let $\rho(p) \equiv p q+(1-p)(1-q)$ be the probability that an informed depositor will receive a favorable signal at that stage given the prior belief. When a depositor receives the signal, he updates his belief according to Bayes' rule: 


$$
p_{i}^{i}(p)= \begin{cases}P_{H}(p)=\frac{p q}{\rho(p)}, & \text { if } S_{i}=H, \\ P_{L}(p)=\frac{p(1-q)}{1-\rho(p)}, & \text { if } S_{i}=L .\end{cases}
$$

As the signal is accurate with probability $q \geq 0.5$, we have $P_{H}(p) \geq p \geq P_{L}(p)$, where the equality holds if and only if $q=0.5$. That is, if a favorable signal is received, a depositor is more confident in the portfolio returns, whereas if an unfavorable signal is received, he is less confident.

If a depositor is not informed at a stage, he still learns some information by observing the informed depositor's action. When depositor 1 makes a decision at stage 1, his decision carries noisy information about the signals he has received. Given depositor 1's strategy, depositor 2's posterior belief at stage 1 is

$$
p_{1}^{2}(p)=\left\{\begin{aligned}
P_{\tilde{H}}(p)=\frac{p\left[\left(1-\theta_{L}^{1}\right)(1-q)+\left(1-\theta_{H}^{1}\right) q\right]}{\left(1-\theta_{L}^{1}\right)[1-\rho(p)]+\left(1-\theta_{H}^{1}\right) \rho(p)}, \\
\text { if depositor 1 waits; } \\
P_{\tilde{L}}(p)=\frac{p\left[\alpha+(1-\alpha)\left(\theta_{L}^{1}(1-q)+\theta_{H}^{1} q\right)\right]}{\alpha+(1-\alpha)\left\{\theta_{L}^{1}[1-\rho(p)]+\theta_{H}^{1} \rho(p)\right\}}, \\
\text { if depositor 1 withdraws. }
\end{aligned}\right.
$$

The denominator of $P_{\tilde{H}}(p)$ is the probability that depositor 1 waits given depositor 1's strategies $\theta_{S_{1}}^{1}$. The numerator is the probability that the bank's portfolio return is high and depositor 1 waits. The same rule applies for $P_{\tilde{L}}(p)$.

After depositor 2 makes his decision, depositor 1 updates his belief (although he has no chance to change his decision) in a similar way, as follows:

$$
p_{2}^{1}(p)=\left\{\begin{aligned}
P_{x_{1}, \tilde{H}}(p)=\frac{p\left[\left(1-\theta_{x_{1}, L}^{2}\right)(1-q)+\left(1-\theta_{x_{1}, H}^{2}\right) q\right]}{\left(1-\theta_{x_{1}, L}^{2}\right)[1-\rho(p)]+\left(1-\theta_{x_{1}, H}^{2}\right) \rho(p)} \\
\text { if depositor 2 waits; } \\
P_{x_{1}, \tilde{L}}(p)=\frac{p\left[\alpha+(1-\alpha)\left(\theta_{x_{1}, L}^{2}(1-q)+\theta_{x_{1}, H}^{2} q\right)\right]}{\alpha+(1-\alpha)\left\{\theta_{x_{1}, L}^{2}[1-\rho(p)]+\theta_{x_{1}, H}^{2} \rho(p)\right\}} \\
\text { if depositor } 2 \text { withdraws. }
\end{aligned}\right.
$$


Again, the denominator of $P_{x_{1}, \tilde{H}}(p)$ is the probability that depositor 2 waits given depositor 2's strategies $\theta_{x_{1}, S_{2}}^{2}$. The numerator is the probability that the bank's portfolio return is high and depositor 2 waits. The same rule applies for $P_{x_{1}, \tilde{L}}(p)$.

\section{Strategies}

The equilibrium strategies are a vector of $\theta=\left(\theta_{S_{1}}^{1}, \theta_{x_{1}, S_{2}}^{2}\right), x_{1}=0,1$, and $S_{1}, S_{2}=L, H$ that solves the depositor's expected utility maximization problem at each node. Working backward, depositor 2, if patient, chooses the withdrawal probability $\theta_{x_{1}, S_{2}}^{2}$ to maximize his expected utility given his observation of depositor 1's action and his own private signal:

$$
\hat{w}^{2}\left(x_{1}, S_{2}\right)=\max _{\theta_{x_{1}, S_{2}}^{2} \in[0,1]} \theta_{x_{1}, S_{2}}^{2} u\left(c^{1}\left(x_{1}, 1\right)\right)+\left(1-\theta_{x_{1}, S_{2}}^{2}\right)\left[p_{2}^{2} u\left(c^{2}\left(x_{1}, 0, \bar{R}\right)\right)+\left(1-p_{2}^{2}\right) u\left(c^{2}\left(x_{1}, 0, \underline{R}\right)\right)\right],
$$

where $p_{2}^{2}=P_{S_{2}}\left(P_{\tilde{L}}\left(p_{0}\right)\right)$ if $x_{1}=1$ and $p_{2}^{2}=P_{S_{2}}\left(P_{\tilde{H}}\left(p_{0}\right)\right)$ otherwise. The first term on the righthand side is the payoff if he withdraws given depositor 1's action. The second term in the closed bracket is the expected utility if he waits.

For depositor 1, if he does not withdraw at stage 1, his expected utility at the end of stage 2 is

$$
\hat{w}^{1}\left(0, x_{2}, S_{1}\right)=p_{2}^{1} u\left(c^{2}\left(0, x_{2}, \bar{R}\right)\right)+\left(1-p_{2}^{1}\right) u\left(c^{2}\left(0, x_{2}, \underline{R}\right)\right),
$$

where $p_{2}^{1}=P_{0, \tilde{L}}\left(P_{S_{1}}\left(p_{0}\right)\right.$ if $x_{2}=1$ and $p_{2}^{1}=P_{0, \tilde{H}}\left(P_{S_{1}}\left(p_{0}\right)\right.$ otherwise. At stage 1 , depositor 1 chooses withdrawal probability $\theta_{S_{1}}^{1}$ to maximize his expected utility given the probability that depositor 2 will withdraw (i.e., the probability that 1 reaches $\left.\hat{w}^{1}\left(0,1, S_{1}\right)\right)$. This probability, in turn, is partially determined by depositor 1's action, as depositor 2 updates his belief according to what he observes. Depositor 1 solves

$$
\begin{aligned}
\hat{w}^{1}\left(S_{1}\right)= & \max _{\theta_{S_{1}}^{1} \in[0,1]} \theta_{S_{1}}^{1} u\left(c^{1}(1)\right)+ \\
& +\left(1-\theta_{S_{1}}^{1}\right)\left\{\begin{array}{c}
{\left[\alpha+(1-\alpha)\left(\theta_{0, H}^{2} \rho\left(P_{S_{1}}\left(p_{0}\right)\right)+\theta_{0, L}^{2}\left(1-\rho\left(P_{S_{1}}\left(p_{0}\right)\right)\right)\right)\right] \hat{w}^{1}\left(0,1, S_{1}\right)+} \\
(1-\alpha)\left[\left(1-\theta_{0, H}^{2}\right) \rho\left(P_{S_{1}}\left(p_{0}\right)\right)+\left(1-\theta_{0, L}^{2}\right)\left(1-\rho\left(P_{S_{1}}\left(p_{0}\right)\right)\right)\right] \hat{w}^{1}\left(0,0, S_{1}\right)
\end{array}\right\},
\end{aligned}
$$

where the multipliers in front of $\hat{w}^{1}\left(0,1, S_{1}\right)$ and $\hat{w}^{1}\left(0,0, S_{1}\right)$ are the probabilities that depositor 2 withdraws/waits given that depositor 1 receives $S_{1}$ and withdraws.

In equilibrium, depositor 2 infers the investment status by watching depositor 1's action. His belief is updated by his private signal and depositor 1's action. When depositor 1 makes a decision, he also knows his decision will affect depositor 2's belief and decision and, thus, his own payoff. 


\section{Garriga and Gu}

\section{Table 1}

\section{Example of a History-Dependent Contract}

\begin{tabular}{llc} 
Payments to depositors & Variables & Amount \\
\hline Depositor 1 at $t=1$ & $c^{1}(1)$ & 0.9998 \\
Depositor 2 at $t=1$ if 1 withdraws & $c^{1}(1,1)$ & 1.0002 \\
Depositor 2 at $t=1$ if 1 waits & $c^{1}(0,1)$ & 1.0000 \\
Both depositors at $t=2$ if both wait and $R=\bar{R}$ & $c^{2}(0,0, \bar{R})$ & 1.0000 \\
Depositor 1 at $t=2$ if depositor 2 withdraws and $R=\bar{R}$ & $c^{2}(0,1, \bar{R})$ & 1.0001 \\
Depositor 2 at $t=2$ if depositor 1 withdraws and $R=\bar{R}$ & $c^{2}(1,0, \bar{R})$ & 1.0002 \\
Both depositors at $t=2$ if both wait and $R=\underline{R}$ & $c^{2}(0,0, \underline{R})$ & 1.0000 \\
Depositor 1 at $t=2$ if depositor 2 withdraws and $R=\underline{R}$ & $c^{2}(0,1, \underline{R})$ & 0.9997 \\
Depositor 2 at $t=2$ if depositor 1 withdraws and $R=\underline{R}$ & $c^{2}(1,0, \underline{R})$ & 1.0002
\end{tabular}

The solution to maximization problems (7)-(9) given a contract is not necessarily unique. A simple way to illustrate the properties of equilibria is to construct some numerical examples. In all examples in the paper, the utility function is $u(c)=\frac{(c+b)^{\gamma}-b^{\gamma}}{1-\gamma}$, where $b=0.01$ and $\gamma=1.5$. The parameter $b>0$ ensures that marginal utility is bounded low by a positive number when $c=0$. Example 1 shows a case in which a contract has more than one perfect Bayesian equilibrium.

Example 1: Multiple equilibria in the postdeposit game. The parameters in the economy are $\alpha=0.5, \bar{R}=1.3, \underline{R}=0.1, p_{0}=0.5$, and $q=0.7$. Table 1 shows the history-dependent contract considered here.

The contract in the example satisfies the resource constraints (1)-(3). That is, it is a feasible contract but it is not necessarily the best contract that a bank can offer. This contract has two pure strategy perfect Bayesian equilibria. They are

(Equilibrium 1) $\left(\theta_{L}^{1}=0, \theta_{H}^{1}=0, \theta_{1, L}^{2}=1, \theta_{0, L}^{2}=1, \theta_{1, H}^{2}=0, \theta_{0, H}^{2}=0\right)$, and

(Equilibrium 2) $\left(\theta_{L}^{1}=1, \theta_{H}^{1}=0, \theta_{1, L}^{2}=1, \theta_{0, L}^{2}=0, \theta_{1, H}^{2}=0, \theta_{0, H}^{2}=0\right)$.

In the first equilibrium, depositor 1's signal of investment return does not affect his decision. $\mathrm{He}$ always waits if he is patient. Depositor 2 cannot infer any information from depositor 1's action. Thus, depositor 2's decisions are based solely on his private signals, not the withdrawal history.

In the second equilibrium, depositor 1 reacts differently to different signals of investment return. His action partially reveals the signal he has received, which affects depositor 2's decision. Depositor 2's decision is dependent on the withdrawal history.

A banking contract is run proof if $\theta=0$ is the unique solution. If a run-proof contract is provided, depositors do not withdraw unless they are impatient. All other contracts are called run-admitting, as these contracts admit at least one equilibrium in which at least one patient depositor withdraws based on some realization of private signals and withdrawal history. 


\section{THE PREDEPOSIT GAME}

The ex ante expected utility of the depositors is determined by their strategies, which in turn are determined by the contract. Knowing the strategies of the depositors in the postdeposit game given a contract, the representative bank offers a contract that maximizes the ex ante expected utility of the depositors. Given the contract, depositors decide whether to stay in autarky or to deposit at the bank at $t=0$. If the ex ante expected utility in autarky is higher than that under the banking contract, the contract will be accepted and the postdeposit game will be played. Otherwise, depositors prefer to stay in autarky.

\section{Autarky}

In autarky, depositors do not observe each other's actions. A depositor adjusts his investment portfolio after he receives private signals at $t=1$. If the depositor is revealed to be impatient, he immediately consumes all of his available assets and receives utility $u(1)$. A patient depositor's expected utility in period 1 after receiving signal $S$ is solved by

$$
\hat{w}_{1}^{\text {aut }}(S)=\max _{\lambda_{S} \in[0,1]} P_{S}\left(p_{0}\right) u\left(\lambda_{S}+\left(1-\lambda_{S}\right) \bar{R}\right)+\left(1-P_{S}\left(p_{0}\right)\right) u\left(\lambda_{S}+\left(1-\lambda_{S}\right) \underline{R}\right),
$$

where $\lambda_{S}$ denotes the proportion of assets liquidated after receiving the signal.

The ex ante expected utility in autarky is the weighted average of the expected utility in period 1 . That is,

$$
w_{0}^{a u t}=\alpha u(1)+(1-\alpha)\left[\rho\left(p_{0}\right) \hat{w}_{1}^{a u t}(H)+\left(1-\rho\left(p_{0}\right)\right) \hat{w}_{1}^{a u t}(L)\right] .
$$

\section{The Optimal Bank Contract}

The bank's optimal contract maximizes the depositor's ex ante expected utility. As each of the depositors has probability $1 / 2$ of being the first to receive the signals and make a decision, a depositor's ex ante expected utility is the equally weighted expected utilities of depositors 1 and 2 at the beginning of period 1. Let $\hat{w}^{2}\left(x_{1}\right)$ be depositor 2's expected utility at the end of stage 1 given depositor 1's action. Specifically,

$$
\begin{gathered}
\hat{w}^{2}(0)=\alpha u\left(c^{1}(0,1)\right)+(1-\alpha)\left\{\rho\left(P_{\tilde{H}}\left(p_{0}\right)\right) \hat{w}^{2}(0, H)+\left[1-\rho\left(P_{\tilde{H}}\left(p_{0}\right)\right)\right] \hat{w}^{2}(0, L)\right\}, \\
\hat{w}^{2}(1)=\alpha u\left(c^{1}(1,1)\right)+(1-\alpha)\left\{\rho\left(P_{\tilde{L}}\left(p_{0}\right)\right) \hat{w}^{2}(1, H)+\left[1-\rho\left(P_{\tilde{L}}\left(p_{0}\right)\right)\right] \hat{w}^{2}(1, L)\right\} .
\end{gathered}
$$

The depositor's ex ante expected utility is given by

$$
\begin{aligned}
w_{0}= & \frac{1}{2}\left\{\alpha u\left(c^{1}(1)\right)+(1-\alpha)\left[\rho\left(p_{0}\right) \hat{w}^{1}(H)+\left(1-\rho\left(p_{0}\right)\right) \hat{w}^{1}(L)\right]\right\} \\
& +\frac{1}{2}\left\{\begin{array}{c}
(1-\alpha)\left[\rho\left(p_{0}\right)\left(1-\theta_{H}^{1}\right)+\left(1-\rho\left(p_{0}\right)\right)\left(1-\theta_{L}^{1}\right)\right] \hat{w}^{2}(0)+ \\
{\left[\alpha+(1-\alpha)\left[\rho\left(p_{0}\right) \theta_{H}^{1}+\left(1-\rho\left(p_{0}\right)\right) \theta_{L}^{1}\right]\right] \hat{w}^{2}(1)}
\end{array}\right\},
\end{aligned}
$$




\section{Garriga and Gu}

\section{Table 2}

Example of an Optimal Run-Admitting Contract

\begin{tabular}{lcccc}
$\hat{\omega}_{0}$ & $c^{1}(1)$ & $c^{1}(1,1)$ & $c^{2}(1,0, \bar{R})$ & $c^{2}(1,0, \bar{R})$ \\
18.0546 & 1.0064 & 0.9936 & 1.1924 & 0.7949 \\
$c^{1}(0,1)$ & $c^{2}(0,1, \bar{R})$ & $c^{2}(0,1, \underline{R})$ & $c^{2}(0,0, \underline{R})$ & $c^{2}(0,0, \bar{R})$ \\
1.0296 & 1.1644 & 0.7763 & 0.8000 & 1.2000 \\
\hline
\end{tabular}

where the multipliers in front of $\hat{w}^{2}(0)$ and $\hat{w}^{2}(1)$ are the ex ante probabilities that depositor 1 will wait or withdraw.

The representative bank offers a feasible contract that maximizes the ex ante expected utility of the depositors. That is, the bank seeks $c=\left(c^{1}(1), c^{1}\left(x_{1}, 1\right), c^{2}\left(x_{1}, x_{2}, R\right)\right)$ to solve

$$
\begin{gathered}
\hat{w}_{0}=\max _{c} w_{0} \\
\text { st }(1)-(3) .
\end{gathered}
$$

The optimal contract will be accepted at $t=0$ if and only if $\hat{w}_{0} \geq w_{0}^{\text {aut }}$. The analytical solution to the optimal contract is complicated to solve, so numerical examples are used to illustrate the properties of a pure strategy equilibrium under an optimal banking contract. As demonstrated in the previous section, one of the challenges is the multiplicity of equilibria in the postdeposit game. Unfortunately, the conditions for the uniqueness of the equilibrium are too complicated to derive. In the following examples, we check numerically that the optimal contract allows for a unique equilibrium in the postdeposit game. $\underline{13}, \underline{14}$ Examples 2 and 3 illustrate two different cases of an optimal contract; one is run admitting and the other is run proof.

Example 2: The optimal banking contract is run admitting. Parameters in this example are $\alpha=0.6, \bar{R}=1.2, \underline{R}=0.8, p_{0}=0.75$, and $q=0.9$. Table 2 describes the payment scheme that an optimal bank contract provides.

Given this contract, the equilibrium strategies of depositors in the postdeposit game, if patient, are $\theta_{L}^{1}=1, \theta_{H}^{1}=0, \theta_{1, L}^{2}=1, \theta_{0, L}^{2}=0, \theta_{1, H}^{2}=0$, and $\theta_{0, H}^{2}=0$. Given the equilibrium strategies, we can calculate the probability of bank runs. Some bank runs are partial—only one of the depositors withdraws but he does not need to consume immediately; some are full bank runsboth depositors withdraw regardless of their consumption types. The probability of having a partial run conducted by depositor 1 in this example is $\operatorname{Pr}(1$ is patient $) \operatorname{Pr}\left(S_{1}=L\right) \operatorname{Pr}\left(2\right.$ is impatient or $\left.S_{2}=H\right)=0.0864$. The partial run conducted by depositor 2 happens with probability $\operatorname{Pr}(1$ is impatient and 2 is patient $) \operatorname{Pr}\left(S_{2}=L\right)=0.072$. The probability of a full bank run is $\operatorname{Pr}(1$ and 2 are patient $) \operatorname{Pr}\left(S_{1}=S_{2}=L\right)=0.0336$.

We also report the strategies of a depositor in autarky and compare the welfare in autarky with that under the optimal contract. In autarky, a depositor leaves all assets invested if a favorable signal is received and liquidates all assets when an unfavorable signal is received. The consumption of a depositor contingent on the signals and the return is summarized as follows: $\left\{c_{1}=1, c_{2}(H, \bar{R})=1.2, c_{2}(H, \underline{R})=0.8, c_{2}(L, \bar{R})=1\right.$, and $\left.c_{2}(L, \underline{R})=1\right\}$. The ex ante expected utility in autarky, $w_{0}^{\text {aut }}$, is 18.0540 , which is lower than $\hat{w}_{0}$. Hence, the contract will be accepted, although bank runs will take place with positive probability. 


\section{Table 3}

\section{Example of a Run-Proof Contract}

\begin{tabular}{lcccc}
$\hat{\omega}_{0}$ & $c^{1}(1)$ & $c^{1}(1,1)$ & $c^{2}(1,0, \bar{R})$ & $c^{2}(1,0, \underline{R})$ \\
18.0383 & 1.0053 & 0.9947 & 1.1936 & 0.7957 \\
$c^{1}(0,1)$ & $c^{2}(1,0, \bar{R})$ & $c^{2}(1,0, \underline{R})$ & $c^{2}(0,0, \bar{R})$ & $c^{2}(0,0, \underline{R})$ \\
1.0116 & 1.1861 & 0.7907 & 0.2000 & 1.8000 \\
\hline
\end{tabular}

The signals are 90 percent accurate in this example. In autarky, since the signal is highly accurate, a depositor will follow the signal. In the banking economy, a private signal still plays an important role-depositor 1 follows the signal as he would in autarky since he must make decisions before he learns information from depositor 2. However, depositor 2 infers information from depositor 1's action and depositor 2 does not rely solely on his private signals to make a withdrawal decision. Depositor 1's decision to wait reveals that a favorable signal has been received. If depositor 2 receives an unfavorable signal, it will be offset by the favorable signal inferred and his posterior belief will become $p_{0}$. As $p_{0}$ still is fairly favorable, depositor 2 will not withdraw. If depositor 1 withdraws, however, the action sends noisy information that an unfavorable signal may be received. When depositor 2 receives an unfavorable signal, his belief is lowered even more, such that he prefers to liquidate the asset immediately to mitigate the loss in investment. But if depositor 2 gets a favorable signal, his posterior belief becomes higher than $p_{0}$. In this case, he still follows his private signal and waits.

A run-admitting bank contract is optimal in some economies for the following reasons. First, the contract helps smooth the consumption in an economy with aggregate consumption shocks. Second, in an economy with production uncertainty, a bank run is not necessarily bad. In example 2, if the true state of productivity is low, then depositors receive payments in the amount of either 1.0064 or 0.9936 . But if both depositors wait, each will get 0.8000 . A bank run is a means to terminate low-quality investments to mitigate future losses. In this sense, information about investment return is valuable and a run-admitting contract allows information to be partially revealed.

In example 2, the partial run conducted by depositor 2 relies on the fact that depositor 1 withdraws. Because of imperfect signals and the revelation of imperfect information by actions, a bank run can occur when productivity is actually high. If the probability of a bank run in a high-return state is too high, a run-proof contract will be offered by the bank. Example 3 illustrates this precise case. When the signal received by depositors contains too much noise, a runproof contract is optimal.

Example 3: The optimal banking contract is run proof. The parameters in this economy are the same as in example 2 except that $q=0.5$. In this case, a productivity signal is not informative. Table 3 describes the payment scheme of the optimal banking contract.

Given such a contract, there is a unique equilibrium in the postdeposit game in which depositors withdraw if and only if they are impatient.

In autarky, depositors leave all assets invested if they are patient. The private signal does not carry any information and if a depositor decides to invest ex ante, he will not change his decision if he is patient, as no useful information arrives ex post. The ex ante expected utility in autarky 


\section{Garriga and Gu}

\section{Figure 1}

\section{Expected Utilities in Autarky and Under an Optimal Deposit Contract}

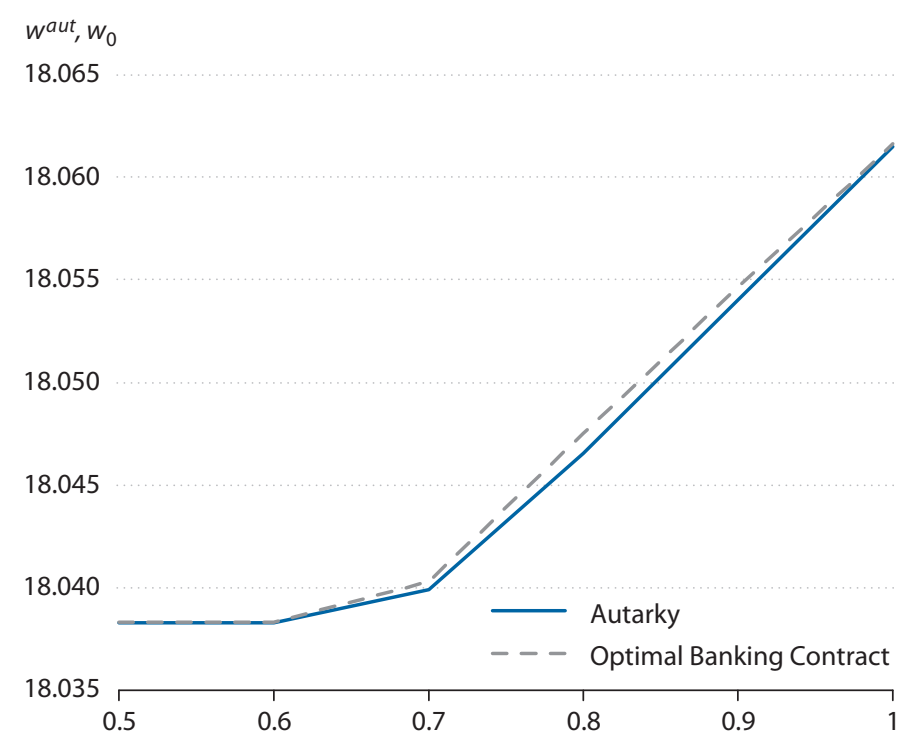

is 18.0383 , which is equivalent to that in the banking economy. Depositors weakly prefer to accept the contract and no bank run occurs ex post. Because the signals carry too much noise in a banking economy, if a run-admitting contract were provided, bank runs would happen too often when the fundamentals are strong. Therefore, a contract that does not allow for the disclosure of information is more desirable here. Compared with example 2 , the contract here provides less consumption to the first depositor who withdraws in $t=1$ (i.e., $c^{1}(1)$ and $c^{1}(0,1)$ ). The lower payments in $t=1$ discourage depositors from withdrawing even when they receive unfavorable signals (although signals are not useful in predicting returns in this case). On the contrary, payments of $c^{1}(1)$ and $c^{1}(0,1)$ in example 2 are higher, so depositors are more encouraged to withdraw when the signals are unfavorable. As a result, depositors partially reveal their signals by their actions.

Figure 1 plots the expected utilities in autarky and under the optimal contract with different values of $q$ given other parameters in example 2. $\underline{15}$ The dashed line represents the expected utility under the optimal banking contract, whereas the solid line represents the expected utility in autarky.

When $q$ is small, the contract is run proof and the expected utility is the same as in autarky. As $q$ increases, the optimal banking contract is run admitting and yields strictly higher expected utility than autarky. The difference in expected utilities between a banking economy and autarky is not monotone: As $q$ approaches 1, the welfare gain in the banking economy decreases ( $w^{\text {aut }}=18.0615$ and $\hat{w}_{0}=18.0616$ if $q=1$ ). Why is that? In our model, depositors gain from participating in banking through two functions of the bank. First, the bank provides consumption insurance for depositors as noted in the literature (see, for example, Diamond and Dybvig, 1983). Second, the bank provides additional information on fundamentals to depositors since with- 


\section{Table 4}

\section{Example of an Optimal Contract When Investment Return Signals Are Public}

$\begin{array}{lc}c^{1}(1, H) & c^{1}(1, L) \\ 1.0084 & 0.9990 \\ c^{1}(0,1, H, H) & c^{1}(0,1, H, L) \\ 1.0271 & 1.0106 \\ c^{2}(1,0, H, H, \bar{R}) & c^{2}(1,0, H, H, \underline{R}) \\ 1.1899 & 0.7933 \\ c^{2}(1,0, L, H, \bar{R}) & c^{2}(1,0, L, H, \underline{R}) \\ 1.2012 & 0.8008 \\ c^{2}(0,0, H, H, \bar{R}) & c^{2}(0,0, H, H, \underline{R}) \\ 1.2000 & 0.8000 \\ c^{2}(0,0, L, H, \bar{R}) & c^{2}(0,0, L, H, \underline{R}) \\ 1.2000 & 0.8000 \\ c^{2}(0,1, H, H, \bar{R}) & c^{2}(0,1, H, H, \underline{R}) \\ 1.1675 & 0.7784 \\ c^{2}(0,1, L, H, \bar{R}) & c^{2}(0,1, L, H, \underline{R}) \\ 1.1873 & 0.7915\end{array}$
$c^{1}\left(1,1, H, S_{2}\right)$ 0.9916
$C^{1}(0,1, L, H)$ 1.0106
$c^{2}(1,0, H, L, \bar{R})$
1.1899
$c^{2}(1,0, L, L, \bar{R})$
1.0010
$c^{2}(0,0, H, L, \bar{R})$
1.2000
$c^{2}(0,0, L, L, \bar{R})$
1
$c^{2}(0,1, H, L, \bar{R})$
1.1873
$c^{2}(0,1, L, L, \bar{R})$
1.0016
$c^{1}\left(1,1, L, S_{2}\right)$ 1.0010
$c^{1}(0,1, L, L)$ 0.9984
$c^{2}(1,0, H, L, \underline{R})$
0.7933
$c^{2}(1,0, L, L, \underline{R})$ 1.0010
$c^{2}(0,0, H, L, \underline{R})$ 0.8000
$c^{2}(0,0, L, L, \underline{R})$
1
$c^{2}(0,1, H, L, \underline{R})$
0.7915
$c^{2}(0,1, L, L, \underline{R})$ 1.0016

drawals are publicly observable. In autarky, depositors observe only their own signals. When $q=1$ (i.e., signals are perfect), observing the other depositors' actions does not provide additional information. Therefore, the gain from information aggregation disappears in this extreme case.

\section{PUBLIC SIGNALS}

To illustrate that the economy is inefficient because the information on investment is private, it is useful to solve a numerical example with public signals on portfolio returns and compare it with an example with private signals. Here we continue with example 2 but with the conditions that the signals on investment return are now publicly observable, although consumption signals are private.

Example 4: Public signals on investment return. In this example, the signals on investment return are publicly observable. Depositors have private information about their consumption types. The contract specifies the payments contingent on a depositor's arrival time, the withdrawal history, and the public signals. The parameters are the same as in example 2. Table 4 shows the optimal payment scheme. The expected utility under the optimal payment scheme is $\hat{w}_{0}^{*}=18.0567$, which is higher than that in the economy with private investment return signals.

The strategies of depositors under the optimal contract are $\theta=0$. That is, no patient depositor withdraws. The optimal payment scheme given public information encourages depositors to truthfully report their consumption types by their actions. Given any public history, the expected utility of a depositor in the last period is higher than the utility from immediate withdrawal. Although there are two sources of uncertainties in our model, the bank and depositors share the same information regarding investment return. In other words, the only information 


\section{Garriga and Gu}

asymmetry between the bank and the depositors comes from consumption types. Now the bank's only requirement is to design an incentive-compatible contract to eliminate bank runs. Similar to Green and Lin's $(2000,2003)$ findings, a contract contingent on the withdrawal history can prevent bank runs by eliminating the asymmetric information between the bank and depositors.

Another lesson from this example is that the direct revelation rule is, in general, not incentive compatible in the environment with private signals of investment return. Suppose that depositors must announce their private signals (direct revelation) before they make decisions at $t=1$.

Depositors have incentives to lie (violate incentive compatibility) to the bank when they receive an unfavorable signal. A depositor can instead tell the bank that although he has received a favorable signal, he needs to consume immediately. If the bank believes him, he could receive a larger payment than he should. Example 4 illustrates this point. Suppose depositor 1 is patient. He receives an unfavorable signal and he reports truthfully. Depositor 2 is also patient and he also receives an unfavorable signal. If he reveals the true signal and does not withdraw at $t=1$, he will receive $c^{2}(0,0, L, L, \bar{R})=c^{2}(0,0, L, L, \underline{R})=1.0016$ in the last period, whereas if he claims to be impatient but has received a favorable signal, he will receive $c^{1}(0,1, L, H)=1.0106$.

\section{CONCLUSION}

This paper provides a simple model to understand the dynamics during bank runs in an environment in which depositors have private information on bank fundamentals and the deposit contract can be made contingent on withdrawal history. Given such a contract, there is a perfect Bayesian equilibrium in which depositors' beliefs and actions are affected by the actions of others. Under certain parameterizations, the computed examples indicate that the optimal bank contract tolerates bank runs. Runs are tolerated because they are triggered by unfavorable signals on bank portfolios and liquidating unsuccessful investments early can prevent future losses. Because the signals are private, a depositor's action is the only way to partially reveal his private information. A run-admitting contract allows information to be revealed.

Nevertheless, if signals are too noisy, bank runs may occur too often when fundamentals are strong. In this case, the bank would offer a run-proof contract. Given the relevant role of information, a policy that can make private information public would be useful to improve the welfare and eliminate bank runs.

One of the model's main limitations is that the bank has no information on investment. A more sophisticated model in which the bank receives signals on investment would prompt more interesting questions, such as how to eliminate a bank's moral hazard incentives related to the information asymmetry between the bank and its depositors and how the bank can reduce the probability of bank runs resulting from incorrect signals.

\section{NOTES}

1 See Allen and Gale (1994), Goldstein and Pauzner (2005), and Gu (2011).

$\underline{2}$ The sunspot signals can be viewed as the uncertainty in the fundamentals taken to the limit (as in Manuelli and Peck, 1992). 
3 Brunnermeier (2001, p. 214) says that "Although withdrawals by deposit holders occur sequentially in reality, the literature typically models bank runs as a simultaneous move game."

4 Special finance houses are like commercial banks, but their deposits are not insured.

5 Also see Schumacher (2000) for details on the 1994-95 Argentine banking crisis.

6 Bank runs here have the features of the herd effect (Banerjee, 1992, and Bikhchandani, Hirshleifer, and Welch, 1992).

7 Unlike Green and Lin (2000, 2003), the asymmetric information between the bank and depositors cannot be fully eliminated by depositors' simple zero-one (i.e., withdrawal-or-wait) decisions.

8 See Anderson (2009) for pricing risk.

9 This result agrees with the findings of Green and Lin $(2000,2003)$ and Andolfatto, Nosal, and Wallace (2007) that the payment schedules contingent on withdrawal history can eliminate bank runs in an economy with i.i.d. consumption shocks.

10 Besides the additional dimension of uncertainty, there are two other distinctions between Green and Lin's (2000, 2003) setup and ours. First, Green and Lin use a direct revelation mechanism in which depositors report their private information about consumption types to the bank. The direct revelation mechanism is not feasible in an economy with two dimensions of uncertainty - the bank makes a bigger payment if the future return is higher. So a depositor would always report that he receives a favorable signal on the bank's portfolio when he decides to withdraw. Second, depositors do not observe the decisions of others in Green and Lin's economy but they do in ours. Whether a decision is observable is not crucial to Green and Lin's model (see Andolfatto, Nosal, and Wallace, 2007). However, it is crucial in our model because the observed withdrawals provide information on fundamentals.

11 In a similar model setup, Gu (2011) studies the herding effect on bank runs given a simple demand deposit contract.

12 The consideration of a payment scheme contingent on history has been widely discussed in the banking literature. See Diamond and Dybvig (1983) for details on full suspension of convertibility in an economy with no aggregate uncertainty and Wallace (1990) for partial suspension of convertibility. Green and Lin $(2000,2003)$ show that in a finite economy with i.i.d. consumption shocks, the optimal banking contract that pays depositors depending on their arrival time and the withdrawal history can completely eliminate panic-based bank runs.

$\underline{13}$ Only pure strategy equilibria are considered. The expected utility under a true optimal contract (that is, if we consider a mixed strategy equilibrium) can be higher. However, considering mixed strategies significantly complicates computation. Note that the strategies under a run-proof contract are pure strategies. Hence, the bottom line is that the optimal contract is not run proof in some economies (example 2), while it is optimal in others (example 3).

14 We check the uniqueness in the following way: There are 27 possible pure strategy profiles. We compute the bank's optimal contract given each strategy profile and then check whether the given strategy profile is the equilibrium strategy under the computed optimal contract. And if so, whether the ex ante expected utility is higher than that under autarky. In all the numeric examples in the paper, only one of the 27 cases is the equilibrium strategy and yields ex ante expected utility higher than the autarky. Hence, it is sufficient to conclude the optimal contract allows for a unique equilibrium.

15 Again, only pure strategy equilibria are considered. The bottom line is that when $q$ increases, the optimal contract is no longer run proof.

\section{REFERENCES}

Allen, Franklin, and Gale, Douglas. "Limited Market Participation and Volatility of Asset Prices." American Economic Review, September 1994, 84(4), pp. 933-55.

Anderson, Richard G. "Bagehot on the Financial Crises of 1825...and 2008." Federal Reserve Bank of St. Louis Monetary Trends, February 2009; http://research.stlouisfed.org/publications/mt/20090201/cover.pdf.

Anderson, Richard G. and Gascon, Charles G. "The Commercial Paper Market, the Fed, and the 2007-2009 Financial Crisis." Federal Reserve Bank of St. Louis Review, November/December 2009, 91(6), pp. 589-612; http://research.stlouisfed.org/publications/review/article/7857.

Andolfatto, David; Nosal, Ed and Wallace, Neil. "The Role of Independence in the Diamond-Dybvig Green-Lin Model." Journal of Economic Theory, November 2007, 137(1), pp. 709-15. 


\section{Garriga and Gu}

Banerjee, Abhijit V. "A Simple Model of Herd Behavior." Quarterly Journal of Economics, August 1992, 107(3), pp. 797-817.

Bikhchandani, Sushil; Hirshleifer, David and Welch, Ivo. "A Theory of Fads, Fashion, Custom, and Cultural Change as Informational Cascades." Journal of Political Economy, October 1992, 100(5), pp. 992-1026.

Brunnermeier, Markus. Asset Pricing under Asymmetric Information-Bubbles, Crashes, Technical Analysis, and Herding. Oxford, UK: Oxford University Press, 2001.

Diamond, Douglas and Dybvig, Philip. "Bank Runs, Deposit Insurance, and Liquidity." Journal of Political Economy, June 1983, 91(3), pp. 401-19.

Goldstein, Itay and Pauzner, Ady. "Demand-Deposit Contracts and the Probability of Bank Runs." Journal of Finance, June 2005, 60(3), pp. 1293-327.

Gorton, Gary. Slapped by the Invisible Hand: The Panic of 2007. New York: Oxford University Press, 2010.

Green, Edward J. and Lin, Ping. "Diamond and Dybvig's Classic Theory of Financial Intermediation: What's Missing?" Federal Reserve Bank of Minneapolis Quarterly Review, Winter 2000, 24(1), pp. 3-13; www.minneapolisfed.org/research/qr/qr2411.pdf.

Green, Edward J. and Lin, Ping. "Implementing Efficient Allocations in a Model of Financial Intermediation." Journal of Economic Theory, March 2003, 109(1), pp. 1-23.

Gu, Chao. “Herding and Bank Runs." Journal of Economic Theory, January 2011, 146(1), pp. 163-88.

Manuelli, Rodolfo and Peck, James. "Sunspot-like Effects of Random Endowments." Journal of Economic Dynamics and Control, April 1992, 16(1), pp. 193-206.

Peck, James and Shell, Karl. "Equilibrium Bank Runs." Journal of Political Economy, February 2003, 111(1), pp. $103-23$.

Schumacher, Liliana. “Bank Runs and Currency Run in a System without a Safety Net: Argentina and the 'Tequila' Shock." Journal of Monetary Economics, August 2000, 46(1), pp. 257-77.

Starr, Martha and Yilmaz, Rasim. "Bank Runs in Emerging-Market Economies: Evidence from Turkey's Special Finance Houses." Southern Economic Journal, April 2007, 73(4), pp. 1112-132.

Wallace, Neil. "A Banking Model in Which Partial Suspension Is Best." Federal Reserve Bank of Minneapolis Quarterly Review, Fall 1990, 14(4), pp. 3-16; www.minneapolisfed.org/research/qr/qr1442.pdf. 


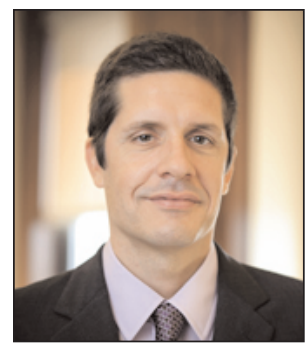

\section{Carlos Garriga}

Research officer and economist, Federal Reserve Bank of St. Louis

http://research.stlouisfed.org/econ/garriga/

\section{Research Focus}

Carlos Garriga's recent research has focused on house price movements, mortgage finance, and the macroeconomic implications of housing. Past research has analyzed the issues of optimal fiscal policy, the design of social security reforms, and the financing of education.

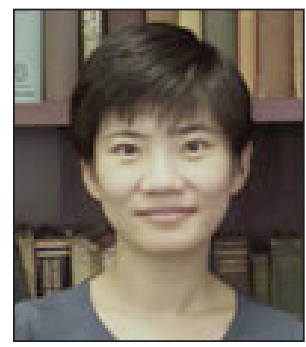

\section{Chao Gu}

Assistant professor of econonics, University of Missouri-Columbia

\section{Research Focus}

Chao Gu's research focuses on money, banking, and credit markets. Her research analyzes bank runs, credit market cycles, pricing in the payment system, and unconventional monetary policy. 